\title{
An Analysis of the Perspective of People in Training "Conscripted" to Manage COVID-19 Hospital Patients in Mexico
}

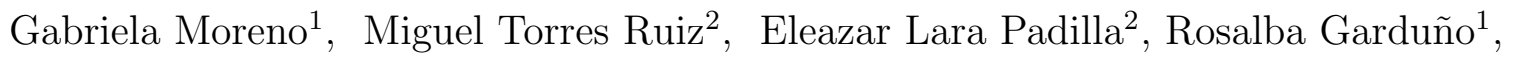 \\ Antonio Franco Vadillo ${ }^{3}$, José de Jesús Peralta Romero ${ }^{4}$, José Bruno Mendoza Ramírez ${ }^{2}$, \\ Adrian Heald ${ }^{5}$, Nilson Contreras Carreto ${ }^{6}$, and Javier Mancilla Ramírez ${ }^{6}$ \\ ${ }^{1}$ Secretaria de Salud de Mexico \\ ${ }^{2}$ Instituto Politecnico Nacional \\ ${ }^{3}$ Instituto Politécnico Nacional \\ ${ }^{4}$ Hospital de Especialidades Centro Médico Nacional Siglo XXI \\ ${ }^{5}$ Salford Royal Hospitals NHS Trust \\ ${ }^{6}$ Secretaría de Salud de Mexico
}

January 31, 2021

\begin{abstract}
Background In order to address the COVID-19 pandemic, health systems have used all their resources, including health care workers in training. Knowing the insights of these workers is of the utmost importance to generate adequate educative/political /administrative strategies. Methods An anonymous cross-sectional online survey was made by the General Directorate of Quality and Health Education in Mexico, in a convenience sample of 6,020 participants who belong to personnel in training for the health area, which included practitioners and professional technologists, undergraduate doctors, nursing, and residents in several specialties. Results Different positive and negative feelings were identified by the health workers who participated in facing this health emergency; emphasizing elements such as the need for Personal Protection Equipment (PPE) that, when deficient or lacking, generate concerns that raise questions about the medical/epidemiological attention to the pandemic. Based on an analysis of feelings, 8 main feelings were identified, which by frequency of appearing were: distrust(24.83\%), fear(21.97\%), sadness(12.45\%), anticipation(11.65\%), anger(10.71\%), disgust(9.69\%), joy(4.97\%) and surprise(3.72\%) which influence health workers in training and their wrok performance day to day. Concerning their positive and negative evaluation of their experience facing this health emergency, $13.83 \%$ of participants had a positive perception about participating in this kind of health emergency to support the country, $49.94 \%$ showed a negative evaluation, and $36.23 \%$ kept a neutral evaluation about their participation. Conclusions The health workers in training in Mexico gave a negative evaluation of the management of the health emergency. Distrust as a response to the absence of timely information from the education/health institutions, as well as concern about lack of personal protection equipment/inputs, are the main conflicts reported. We must establish a credible globally relevant continuity plan for the education of health care personnel in training, facing emergencies and disasters, so that next time we are properly prepared.
\end{abstract}

\section{Hosted file}

Analysis_of_perceptions_2021_(3).pdf available at https://authorea.com/users/392812/articles/ 506594-an-analysis-of-the-perspective-of-people-in-training-conscripted-to-manage-covid19-hospital-patients-in-mexico

Hosted file

Table_1_C19_Paper.pdf available at https://authorea.com/users/392812/articles/506594- 
an-analysis-of-the-perspective-of-people-in-training-conscripted-to-manage-covid-19hospital-patients-in-mexico
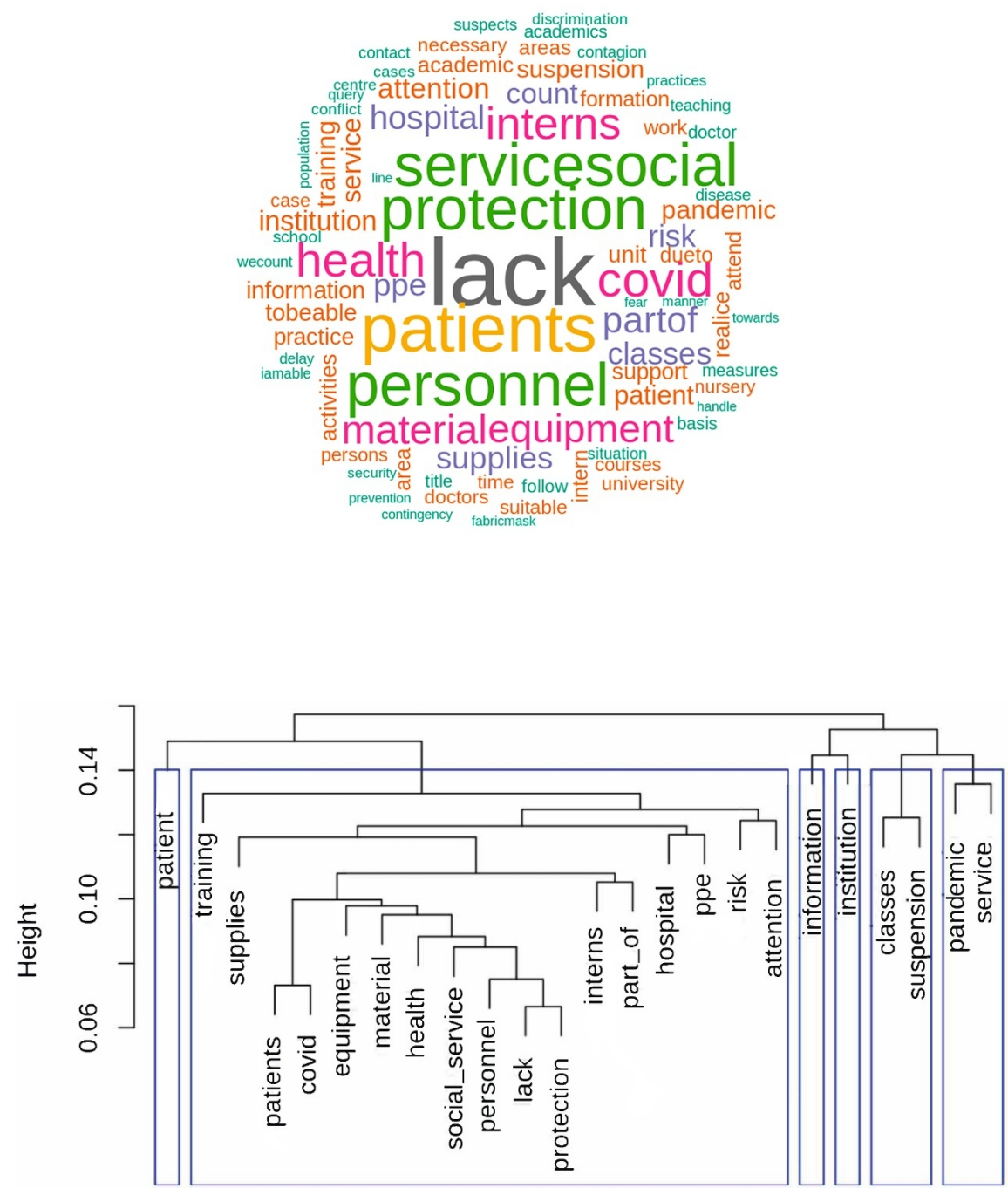